Check for updates

Cite this: RSC Adv., 2018, 8, 37193

Received 5th September 2018 Accepted 29th October 2018

DOI: $10.1039 / \mathrm{c} 8 \mathrm{ra0} 07405 \mathrm{~d}$

rsc.li/rsc-advances

\title{
Modulation of a coordination structure in a europium(III)-based metallo-supramolecular polymer for high proton conduction $\dagger$
}

\author{
Yemineni S. L. V. Narayana, Chanchal Chakraborty, Utpal Rana, Yoshikazu Ninomiya,
} Takefumi Yoshida (iD and Masayoshi Higuchi (D) *

\begin{abstract}
Developing high proton conducting solid materials is significant in the field of fuel cells. A europium(III)based metallo-supramolecular polymer with uncoordinated carboxylic acids (PolyEu-H) was successfully synthesized by modifying the synthesis conditions. The proton conductivity was enhanced with increasing the relative humidity $(\mathrm{RH})$ from 30 to $95 \% \mathrm{RH}$. PolyEu-H showed about $10^{4}$ times higher proton conductivity than the polymer with coordinated carboxylic acids (PolyEu) and about 400 times higher than the polymer without carboxylic acids (PolyEu-2). The proton conductivity of PolyEu-H reached $4.45 \times 10^{-2} \mathrm{~S} \mathrm{~cm}^{-1}$ at $95 \% \mathrm{RH}$ and $25{ }^{\circ} \mathrm{C}$ and $5.6 \times 10^{-2} \mathrm{~S} \mathrm{~cm}^{-1}$ at $75{ }^{\circ} \mathrm{C}$. The activation energy, $E_{a}$ was ultralow $(0.04 \mathrm{eV})$, which indicates proton conduction based on the Grotthuss mechanism. The results indicate that efficient proton conduction occurs through proton channels formed by moisture in PolyEu-H.
\end{abstract}

\section{Introduction}

Metallo-supramolecular polymers (MSPs) have received much attention due to their unique electrochemical properties. ${ }^{1-8}$ MSPs are synthesized by the complexation of metal ions and ditopic ligands. Proton conductive materials are essential for many applications including fuel cells and electrochemical sensors. ${ }^{9-28}$ The proton conductivity is mainly influenced by the mobility of protons through proton channels in the system. MSPs with carboxylic acids have the possibility to form proton channels through the long polymer chains as shown in Fig. 1. Earlier, our research group reported MSPs for ionic and proton conduction applications. ${ }^{29-35}$ We studied the ionic conductivity of Ni(II)-based MSPs under highly humid conditions. ${ }^{29-32}$ We also revealed the proton conductivity of Mobased MSP with carboxylic acids. ${ }^{33}$ In the case of Mo-based MSP, carboxylic acids were introduced by direct oxygenation of methyl groups. However, the oxygenation did not perfectly proceed due to the steric hindrance of the coordination sites in the polymer. So, we tried to investigate another method to introduce carboxylic acids into MSPs efficiently.

Trivalent lanthanides show variable (2-12) and routine large coordination numbers in the complexes. ${ }^{36,37}$ To the best of our knowledge, no report on lanthanide-based MSPs for proton conduction and no one attempted the modulation of

Electronic Functional Macromolecules Group, National Institute for Material Science (NIMS), Tsukuba 305-0044, Japan.E-mail: HIGUCHI.Masayoshi@nims.go.jp

$\dagger$ Electronic supplementary information (ESI) available. See DOI: 10.1039/c8ra07405d coordination structure in $\mathrm{Eu}(\mathrm{III})$-based MSPs. A purpose of this research is the control of coordination number and introduce of carboxylic acids into MSPs to achieve high proton conduction. We have chosen the Eu(III) complex because it has tunable coordination number (2-12). Europium(Eu)-based MSPs (PolyEu, Fig. 3) was prepared by complexation of Eu(III) and bisterpyridine including carboxylic acids. ${ }^{38}$ In this

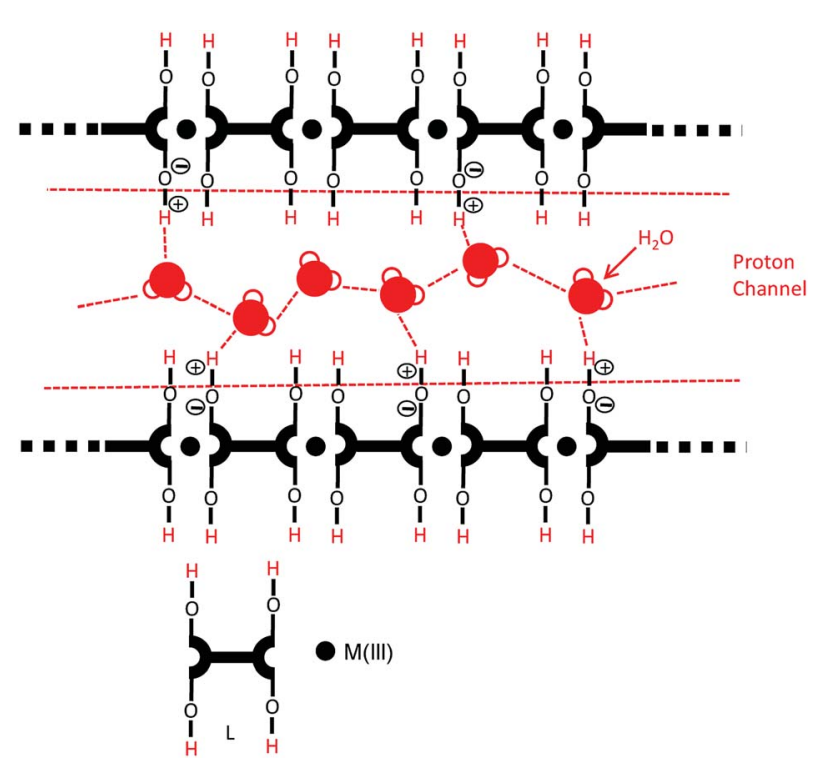

Fig. 1 Anticipated formation of proton channels in MSP with carboxylic acids. 
(a)

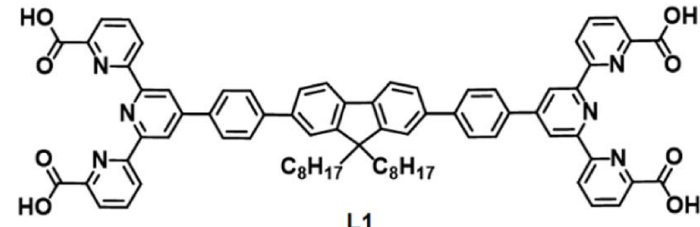

(b)

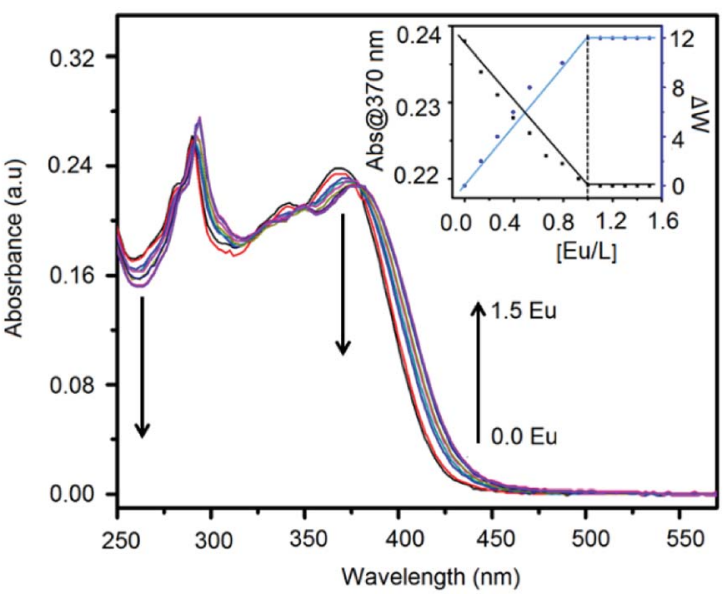

Fig. 2 (a) A structure of $L 1$ (b) the UV/Vis spectral change of L1 during the successive addition of $\mathrm{Eu}\left(\mathrm{NO}_{3}\right)_{3} \cdot 5 \mathrm{H}_{2} \mathrm{O}$ (insets: absorption probed at $365 \mathrm{~nm}$ (black line), wavelength shift $(\Delta W)=W_{\mathrm{i}}-W_{\mathrm{f}}$ (blue line), $W_{\mathrm{i}}=$ $365 \mathrm{~nm}$ ). (Solvent- $\mathrm{CHCl}_{3} / \mathrm{MeOH}$, Concentration-5 $\mu \mathrm{m}$.)

polymer, four carboxylates of the ligand coordinate to the metal, because a base exists in the reaction mixture and supports the Eu-O-C bond formation. However, we expect the carboxylic acids will be uncomplexed in the polymer by modifying the reaction conditions. We herein report modulation of metal-coordination structure in $\mathrm{Eu}(\mathrm{III})$-based MSP for high proton conduction.

\section{Experimental section}

\section{General}

Unless otherwise noted, all reagents were reagent and spectroscopic grade and were used without further purification. 2,2'-(9,9-Dioctyl-9H-fluorene-2,7-diyl)bis(4,4,5,5-tetramethyl1,3,2-dioxaborolane), $\mathrm{Eu}\left(\mathrm{NO}_{3}\right)_{3} \cdot 5 \mathrm{H}_{2} \mathrm{O}$, potassium carbonate, $\mathrm{NaOH}$ and $\mathrm{Pd}\left(\mathrm{PPh}_{3}\right)_{4}$ were purchased from Sigma Aldrich. $4^{\prime}-$ (4-Bromophenyl)-2,2': $6^{\prime}, 2^{\prime \prime}$-terpyridine purchased from Wako chemicals limited. 2,2'-(9,9-Dioctyl-9H-fluorene-2,7-diyl) bis(4,4,5,5-tetramethyl-1,3,2-dioxaborolane) was synthesized from $4^{\prime}$-(4-bromophenyl)-2, $2^{\prime}: 6^{\prime}, 2^{\prime \prime}$-terpyridine using reported procedures. $^{38,39}$ Dry methanol, ethanol, dichloromethane, chloroform, and dimethyl sulfoxide were used as a reaction solvent. These solvents were purchased from Wako or Kanto Chemical Co. Inc. and used as received. Methanol/ $\mathrm{CHCl}_{3}$ and DMSO solvents for UV-Visible and luminescence measurements. De-ionized $\mathrm{H}_{2} \mathrm{O}$ was used in the experiment where required. Silica gel $60 \mathrm{~N}$ was purchased from (neutral, 40-100 $\mu \mathrm{M})$, S2 Kanto Chemical Co. ${ }^{1} \mathrm{H}-\mathrm{NMR}$ and ${ }^{13} \mathrm{C}$-NMR spectra were measured at $300 \mathrm{MHz}$ and $75 \mathrm{MHz}$, respectively, on the JEOL AL 300/BZ instrument. Chemical shifts were assigned relative to TMS. Mass spectra (MS) were measured using AXIMACFR, Shimadzu/Kratos TOF Mass spectrometer. UVVis spectrum was recorded using a Shimadzu UV-2550 UVVisible spectrophotometer. Flash column chromatographic separations were performed on silica gel $60 \mathrm{~N}$ (neutral, 40$100 \mu \mathrm{M})$, S2 Kanto Chemical Co. Inc. The weight average molecular weight of polymers were measured using an SECviscometry-RALLS (size exclusion chromatographyviscometry-right angle laser light scattering) system containing of liquid chromatograph, a pump, solvent degasser refractive index detector, column oven and viscotek 270 dual detector (eluent: DMSO; low speed: $1 \mathrm{~mL} \mathrm{~min}^{-1}$; column temperature: $27{ }^{\circ} \mathrm{C}$ polymer concentration: $1.0 \mathrm{mg} \mathrm{mL}^{-1}$;

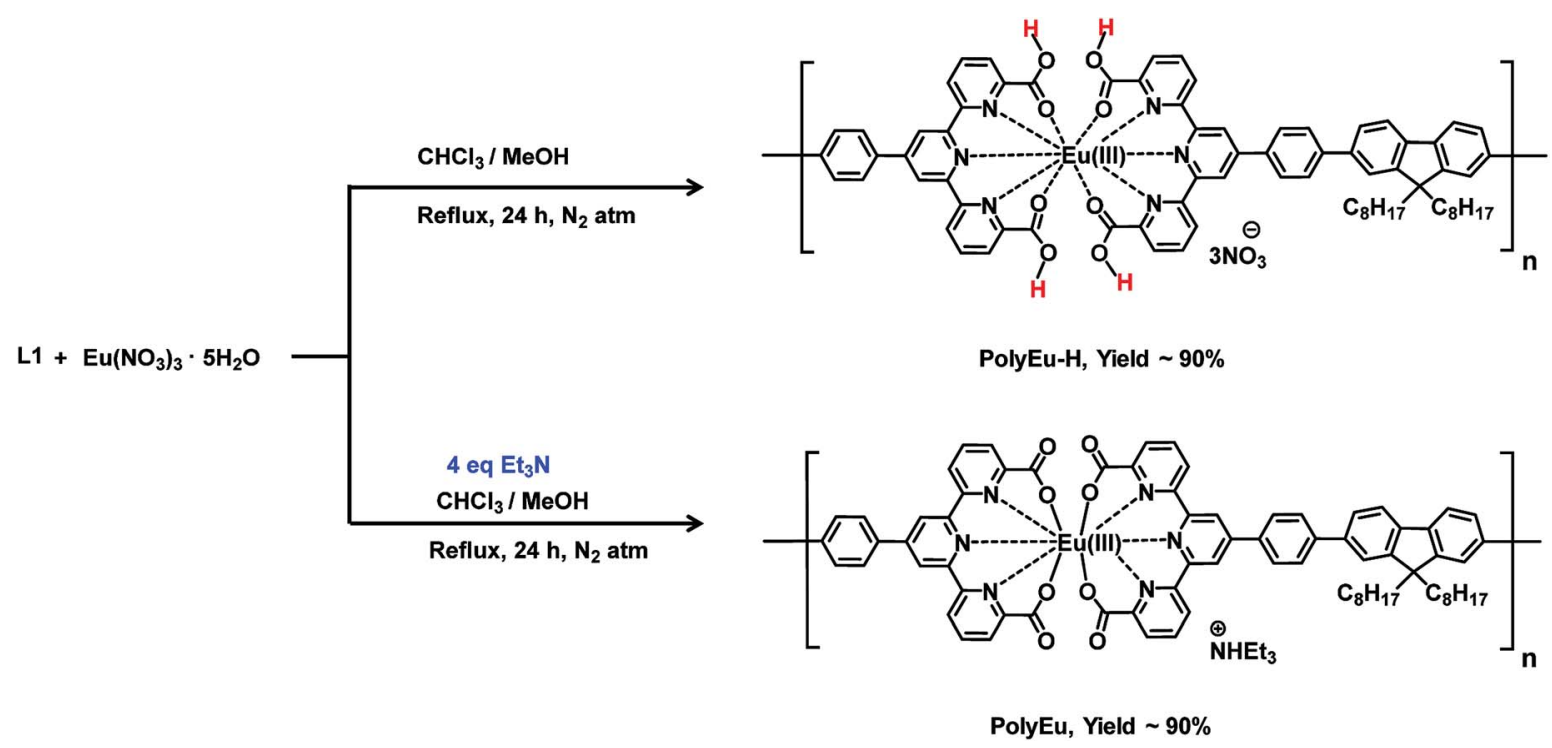

Fig. 3 Synthesis of PolyEu-H and PolyEu. 
injection volume: $20 \mathrm{~mL}$; standard: polyethylene oxide-PEO$19 \mathrm{~K})$. Elemental analyses performed on Elementar vario MiCRO cube. Powder X-ray diffraction (PXRD) was on Rigaku Smart Lab3. Morphological characterization was done by using Atomic force microscopy (AFM) and Scanning electronic microscopy (SEM). Atomic force microscopy in the dynamic mode using Nano Navi II of Seiko Instruments Inc. SII (Si-DF40 cantilever). Scanning electronic microscopy was done using a Hitachi S4800 instrument operating at $10 \mathrm{kV}$ and $10 \mu \mathrm{A}$ current.

\section{Synthesis of $\mathbf{L 1}$}

2,2'-(9,9-Dioctyl-9H-fluorene-2,7-diyl)bis(4,4,5,5-tetramethyl1,3,2-dioxaborolane) $(185 \mathrm{mg}, 0.30 \mathrm{mmol})$, diethyl-4'-(4-bromophenyl)-2,2': $6^{\prime}, 2^{\prime \prime}$-terpyridine-6,6"-dicarboxylate $(350 \mathrm{mg}$, $0.65 \mathrm{mmol})$, potassium carbonate $(140 \mathrm{mg}, 0.9 \mathrm{mmol})$ and $\mathrm{Pd}\left(\mathrm{PPh}_{3}\right)_{4}(34 \mathrm{mg}, 0.033 \mathrm{mmol})$ and DMSO $(50 \mathrm{~mL})$ were added to a $100 \mathrm{~mL}$ two-neck round-bottom flask, and the solution was purged with nitrogen for $15 \mathrm{~min}$. Afterwards the reaction was degassed by a repeated sequence of freezepump-thaw cycles about 1 hour. The solution was stirred at $100{ }^{\circ} \mathrm{C}$ under nitrogen atmosphere for $24 \mathrm{~h}$. After completion of the reaction, the solvent was removed under reduced pressure at $100{ }^{\circ} \mathrm{C}$. The reaction mixture was cooled to room temperature and $\mathrm{CHCl}_{3}(100 \mathrm{~mL})$ was added. The catalyst was removed by filtration and washed thoroughly with $\mathrm{CHCl}_{3}$. The filtrate was then washed with $\mathrm{H}_{2} \mathrm{O}$. The organic layer was separated, dried over $\mathrm{Na}_{2} \mathrm{SO}_{4}$, filtered, concentrated, and purified by column chromatography on silica gel $\left(\mathrm{CHCl}_{3} /\right.$ hexane $\left.=50: 50, R_{\mathrm{f}}=0.72\right)$ afforded tetraester derivative of $\mathrm{L} 1(295 \mathrm{mg}, 49.8 \%) .{ }^{1} \mathrm{H}$ NMR $\left(300 \mathrm{MHz}, \mathrm{CDCl}_{3}, 298 \mathrm{~K}\right) 8.96(\mathrm{~s}$, $4 \mathrm{H}), 8.88(\mathrm{~d}, 4 \mathrm{H}), 8.27(\mathrm{~m}, 4 \mathrm{H}), 8.10(\mathrm{~m}, 8 \mathrm{H}), 7.92(\mathrm{~m}, 6 \mathrm{H})$, $7.75(\mathrm{~m}, 4 \mathrm{H}), 4.58(\mathrm{q}, 8 \mathrm{H}), 2.14(\mathrm{~m}, 4 \mathrm{H}), 1.70(\mathrm{t}, 6 \mathrm{H}), 1.54(\mathrm{~m}$, $24 \mathrm{H}), 1.32(\mathrm{~b}, 24 \mathrm{H}), 0.99(\mathrm{t}, 6 \mathrm{H}) .{ }^{13} \mathrm{C}$ NMR $\left(75 \mathrm{MHz}, \mathrm{CDCl}_{3}\right.$, $298 \mathrm{~K})=167.1,158.2,157.0,153.7,152.0,149.8,144.0,142.1$, $141.5,138.5,130.5,129.0,128.5,127.3,127.0,126.0,125.9$, 125.0, 124.3, 123.1, 122.5, 122.1, 121.0, 120.5, 65.2, 63.5, 61.9, 57.1, 32.8, 31.9, 31.0, 27.2, 25.8, 17.0, 15.1, 13.5. MALDI-TOF: found $m / z: 1293.42[\mathrm{M}+\mathrm{H}] ; \mathrm{C}_{83} \mathrm{H}_{84} \mathrm{~N}_{6} \mathrm{O}_{8}$ requires $(\mathrm{m} / \mathrm{z})$ 1292.64. FT-IR (KBr) cm ${ }^{-1}: 2978(\mathrm{O}-\mathrm{H}), 2926,2852,1742(\mathrm{C}=$ O), $1719(\mathrm{C}=\mathrm{O}), 1605,1583,1542,1520,1455,1420,1391$, 1368, 1308, 1290, 1263, 1198, 1163, 1082, 1024, 991, 934, 901, 820, 775, 744, 723, 697, 646, 627, 596, 544.

\section{Hydrolysis}

To a $10 \mathrm{~mL}$ of THF- $\mathrm{H}_{2} \mathrm{O}(\mathrm{v} / \mathrm{v}=9: 1)$ mixture solution of tetraester derivative of $\mathrm{L} 1(100 \mathrm{mg}, 0.077 \mathrm{mmol})$ was added sodium hydroxide $(12.0 \mathrm{mg}, 0.308 \mathrm{mmol})$ and the mixture was reflux for $16 \mathrm{~h}$. The resulting mixture was cooled at room temperature and then acidified with $2 \mathrm{M}$ hydrochloric acid. The precipitate was filtered and washed with water several times to remove the metal salts. Further, the compound was purified by washing with hexane, ACN, chloroform solvents and dried in vacuo to give as yellow solid of $\mathrm{L} 1(85 \mathrm{mg}, 95 \%) .{ }^{1} \mathrm{H}$ NMR (300 MHz, DMSO, $298 \mathrm{~K}) 8.99$ (s, 4H), 8.88 (d, 4H), 8.18 (m, 8H), $8.04(\mathrm{~m}, 10 \mathrm{H}), 7.90(\mathrm{~s}, 2 \mathrm{H}), 7.89(\mathrm{~d}, 2 \mathrm{H}) 2.17$ (broad,
4H), 1.02 (broad, 24H), 0.69 (t, 6H); HR-MS: found $m / z: 1181.49$ $[\mathrm{M}+\mathrm{H}] ; \mathrm{C}_{71} \mathrm{H}_{68} \mathrm{~N}_{6} \mathrm{O}_{8}[\mathrm{M}]$ requires 1180.51. MALTI-TOF: found $m / z: 1180.47[\mathrm{M}] ; \mathrm{C}_{75} \mathrm{H}_{68} \mathrm{~N}_{6} \mathrm{O}_{8}[\mathrm{M}]$ requires 1180.51. FT-IR $(\mathrm{KBr}) \mathrm{cm}^{-1}$ : 3312 (broad peak, O-H), 3080, 3032, 2926, 2852, $1761(\mathrm{C}=\mathrm{O}), 1721(\mathrm{C}=\mathrm{O}), 1604,1585,1541,1520,1464,1456$, 1421, 1371, 1339, 1258, 1134, 1080, 1013, 993, 894, 836, 817, 778, 745, 671, 641, 621, 598.

\section{Synthesis of $\mathbf{L 2}$}

2,2'-(9,9-Dioctyl-9H-fluorene-2,7-diyl)bis(4,4,5,5-tetramethyl1,3,2-dioxaborolane) (500 mg, $0.89 \mathrm{mmol}$ ), 4'-(4-bromophenyl)-2, $2^{\prime}: 6^{\prime}, 2^{\prime \prime}$-terpyridine $(729 \mathrm{mg}, 1.88 \mathrm{mmol})$, potassium carbonate $(372 \mathrm{mg}, 2.68 \mathrm{mmol})$ and $\mathrm{Pd}\left(\mathrm{PPh}_{3}\right)_{4}(103 \mathrm{mg}, 0.089$ $\mathrm{mmol})$ and DMSO $(60 \mathrm{~mL})$ were added to a $250 \mathrm{~mL}$ two-neck round-bottom flask, and the solution was purged with nitrogen for $30 \mathrm{~min}$. The resultant solution was degassed by a several sequence of freeze-pump-thaw cycles about 30 minutes. The final solution was stirred under nitrogen atmosphere for $24 \mathrm{~h}$, at $100{ }^{\circ} \mathrm{C}$. After 24 hours, the solvent was removed under high vaccum at $100{ }^{\circ} \mathrm{C}$. The crude product was cooled to room temperature and $\mathrm{CHCl}_{3}(200 \mathrm{~mL})$ was added. The palladium catalyst was removed by filtration and washed thoroughly with $\mathrm{CHCl}_{3}$. The organic layer was separated, dried over $\mathrm{Na}_{2} \mathrm{SO}_{4}$, filtered, concentrated, and purified by column chromatography on silica gel $\left(\mathrm{CHCl}_{3} /\right.$ hexane $=50: 50, R_{\mathrm{f}}=$ $0.60)$ afforded the desired product $\mathrm{L} 2(400 \mathrm{mg}, 44 \%) .{ }^{1} \mathrm{H}$ NMR $\left(300 \mathrm{MHz}, \mathrm{CDCl}_{3}, 298 \mathrm{~K}\right) 8.86(\mathrm{~s}, 4 \mathrm{H}), 8.05(\mathrm{~d}, 4 \mathrm{H}), 8.72(\mathrm{~d}, 4 \mathrm{H})$, $8.10(\mathrm{t}, 4 \mathrm{H}), 7.96(\mathrm{~m}, 4 \mathrm{H}), 7.85(\mathrm{~m}, 4 \mathrm{H}), 7.42(\mathrm{~m}, 4 \mathrm{H}), 2.14(\mathrm{~b}$, $4 \mathrm{H}), 1.25(\mathrm{~b}, 24 \mathrm{H}), 0.86(\mathrm{t}, 6 \mathrm{H}) \cdot{ }^{13} \mathrm{C}$ NMR $\left(75 \mathrm{MHz}, \mathrm{CDCl}_{3}, 298\right.$ $\mathrm{K})=157.0,156.0,151.8,150.4,150.0,149.5,147.8,142.0$, $140.0,139.0,137.8,136.8,135.5,128.5,127.0,126.1,124.7$, 123.0, 122.1, 121.0, 120.6, 119.6, 119.0, 117.5, 55.0, 31.5, 30.5, 29.8, 29.0, 28.0, 27.0, 23.5, 22.2, 14.5, 13.0. HR-MS: found $\mathrm{m} / z$ : 1005.49 [M+H]; $\mathrm{C}_{71} \mathrm{H}_{68} \mathrm{~N}_{6}$ requires [M] 1004.55. FT-IR (KBr) $\mathrm{cm}^{-1}: 2924,2852,1652,1605,1572,1540,1469,1428$, 1384, 1286, 1244, 1166, 1014, 891, 819, 792, 738, 683, 661, 636, 624, 549.

\section{Synthesis of PolyEu-H}

An equimolar amount of ligand $\mathrm{L} 1(30 \mathrm{mg}, 0.025 \mathrm{mmol})$ and $\mathrm{Eu}\left(\mathrm{NO}_{3}\right)_{3} \cdot 5 \mathrm{H}_{2} \mathrm{O}(10.88 \mathrm{mg}, 0.025 \mathrm{mmol})$ was heated at $60^{\circ} \mathrm{C}$ in $\mathrm{MeOH} / \mathrm{CHCl}_{3}$ for $24 \mathrm{~h}$ under nitrogen atmosphere. After the reaction mixture was cooled at room temperature, the solvent was removed under vacuum. The product was washed with chloroform, methanol, and hexane. Further, the compound dried in vacuo for overnight to give the corresponding polymer of PolyEu-H as yellow solid (90.0\%). Elemental analysis: found: C, 53.34; H, 5.31; N, 6.27; S, 3.40 calc. for [PolyEu-H $\cdot\left(5 \mathrm{H}_{2} \mathrm{O}+\right.$ $2 \mathrm{DMSO})]=\left(\mathrm{C}_{79} \mathrm{H}_{90} \mathrm{~N}_{9} \mathrm{O}_{24} \mathrm{~S}_{2}\right)_{n}: \mathrm{C}, 53.74 ; \mathrm{H}, 5.14 ; \mathrm{N}, 7.14, \mathrm{~S}, 3.63$. FT-IR (KBr) cm ${ }^{-1}$ : 3385 (broad peak), 3090, 3031, 2923, 2851, $1764(\mathrm{C}=\mathrm{O}$ in $\mathrm{COOH}), 1723(\mathrm{C}=\mathrm{O}$ in $\mathrm{COOH}), 1650,1608,1570$, 1544, 1494, 1451, 1416, 1381, 1270, 1247, 1192, 1167, 1085, 1014, 888, 840, 816, 782, 730, 701, 652, 623. The molecular weight $\left(M_{\mathrm{w}}\right)$ of the polymer was measured using SECViscometry-RALLS method. $M_{\mathrm{w}}=4.0 \times 10^{4} \mathrm{Da}$. 


\section{Synthesis of PolyEu}

Ligand L1 (30 mg, $0.025 \mathrm{mmol}), \mathrm{Et}_{3} \mathrm{~N}(12 \mu \mathrm{L}, 0.099 \mathrm{mmol})$ and $\mathrm{Eu}\left(\mathrm{NO}_{3}\right)_{3} \cdot 5 \mathrm{H}_{2} \mathrm{O}(10.88 \mathrm{mg}, 0.025 \mathrm{mmol})$ was heated at $60{ }^{\circ} \mathrm{C}$ in $\mathrm{MeOH} / \mathrm{CHCl}_{3}(1: 1)$ for $24 \mathrm{~h}$ under the nitrogen atmosphere. The precipitate was filtered and washed with chloroform, methanol, and hexane to remove unreacted ligand and metal. Further, the compound dried in vacuo overnight to give the corresponding polymer of PolyEu as yellow solid (89.0\%). FT-IR $(\mathrm{KBr}) \mathrm{cm}^{-1}$ : 3365 (broad peak), 2953, 2923, 2852, 1611, 1572, 1542, 1452, 1419, 1381, 1268, 1248, 1190, 1177, 1083, 1015, 889, $845,819,787,733,701,653,623$. The molecular weight $\left(M_{\mathrm{w}}\right)$ of the polymer was measured using SEC-Viscometry-RALLS method. $M_{\mathrm{w}}=4.4 \times 10^{4} \mathrm{Da}$.

\section{Synthesis of PolyEu-2}

An equimolar amount of ligand L2 (50 mg, $0.049 \mathrm{mmol}$ ) and $\mathrm{Eu}\left(\mathrm{NO}_{3}\right)_{3} \cdot 5 \mathrm{H}_{2} \mathrm{O}(21 \mathrm{mg}, 0.049 \mathrm{mmol})$ was heated at $60{ }^{\circ} \mathrm{C}$ in $\mathrm{MeOH} / \mathrm{CHCl}_{3}$ for $24 \mathrm{~h}$ under the nitrogen atmosphere. After the reaction mixture was cooled at room temperature, the solvent was removed under vacuum. Further, the compound dried in vacuo overnight to give the corresponding polymer of PolyEu-2 as yellow solid (91.0\%). Elemental analysis: found: C, 63.19; $\mathrm{H}$, 5.37; N, 9.07 calc. for PolyEu-2 $=\left(\mathrm{C}_{71} \mathrm{H}_{68} \mathrm{~N}_{9} \mathrm{O}_{9} \mathrm{Eu}\right)_{n}$ : C, 63.48; H, 5.10; N, 9.38. FT-IR (KBr) cm ${ }^{-1}: 3410$ (broad peak), 2927, 2852, 1612, 1572, 1545, 1495, 1453, 1420, 1384, 1299, 1273, 1249, 1178, 1125, 1088, 1049, 1017, 893, 819, 785, 733, 701, 653, 605, 565 , 526. The molecular weight $\left(M_{\mathrm{w}}\right)$ of the polymer was measured using SEC-Viscometry-RALLS method. $M_{\mathrm{w}}=3.9 \times$ $10^{4} \mathrm{Da}$.

\section{Proton conductivity measurement}

The conductivities of polymers (PolyEu-H, PolyEu, and PolyEu2) pellet (powder samples) were determined by an ac impedance technique. A Solartron 1260 Impedance gain/phase analyser coupled with a Solartron 1296 dielectric interface was used for the measurements. The pellet thickness of all the polymers was in the range of $0.01-0.03 \mathrm{~cm}$. A frequency range of $1 \mathrm{~Hz}$ to 30 $\mathrm{MHz}$ was used to calculate the resistance of the pellet under humid conditions. To estimate the proton conductivity, we used the relation $\sigma=L /(A R)$ equation, where $R$ is the resistance (obtained from the Nyquist plot), $L$ is the width, and $A$ is the area of the sample. These polymers (PolyEu-H, PolyEu, and PolyEu-2) pellets were inserted between the two electrodes of a sample holder $\mathrm{SH}-2 \mathrm{Z}$ from Toyo industries, Tokyo, Japan for their exact conductivity measurement. The setup comprises a guard ring on the electrode to abolish the consequence of stray field lines. The sample holder was attached to a sensitive micrometre for pellet thickness measurements. The whole setup was then placed inside a humidity-temperature controller SH-221 of Espec, Japan. Proceeding to each measurement, the pellets were kept for at least 2-3 hours at a desired temperature and humidity condition. Subsequently, the conductivity was measured using a Solartron 1260.

\section{Results and discussion}

Complexation behavior of L1 (Fig. 2a) and L2 (Fig. 4) with $\mathrm{Eu}\left(\mathrm{NO}_{3}\right)_{3} \cdot 5 \mathrm{H}_{2} \mathrm{O}$ was monitored by UV-Vis spectroscopic measurements by stepwise addition of metal to the corresponding ligand and showed in Fig. $2 \mathrm{~b}$ and S14 (ESI). $\dagger$ All the ligands and metal solutions were prepared to $5 \mu \mathrm{m}$ concentration. Complexation of ligand (L1) and Eu(III) ions resulted in a decrease in the ligand absorbance at around $370 \mathrm{~nm}$ (L1) and shoulder of this band got redshifted. The similar trend of absorbance shifting is also demonstrated at 290 and $\sim 260 \mathrm{~nm}$. The redshifts of peaks probably due to conformational changes of ligand structure during the complexation. Moreover, the stoichiometric ratio of the complexation was determined by plotting of the absorbance at $370 \mathrm{~nm}$ and wavelength shift at same wavelength $v s$. the ratio of metal (1:1) (inset of Fig. 2b) to ligand and it showed a linear decrease and a sharp end point at the ratio of $1: 1(\mathrm{~L} 1: \mathrm{Eu}(\mathrm{III}))$, representing the MSP was successfully formed. Similarly, we also investigated the complexation behavior of $\mathrm{L} 2$ with $\mathrm{Eu}(\mathrm{III})$. Complexation of L2 and $\mathrm{Eu}(\mathrm{III})$ ions resulted in a decrease in the ligand absorbance at around $350 \mathrm{~nm}$ (L2) and shoulder of this band got redshifted as well as absorbance at $290 \mathrm{~nm}$ (Fig. S14 in ESI $\dagger$ ). Again, the complexation is very stable as the corresponding absorbance after saturation point (1:1 complexation) is not altered after the addition of excess metal ions. The comparative absorption spectra of ligands (L1 and L2) and their MSPs were presented in Fig. S16 (ESI). $\dagger$ We also observed different emission color of polymers. PolyEu, PolyEu-H, and PolyEu-2 showed reddish
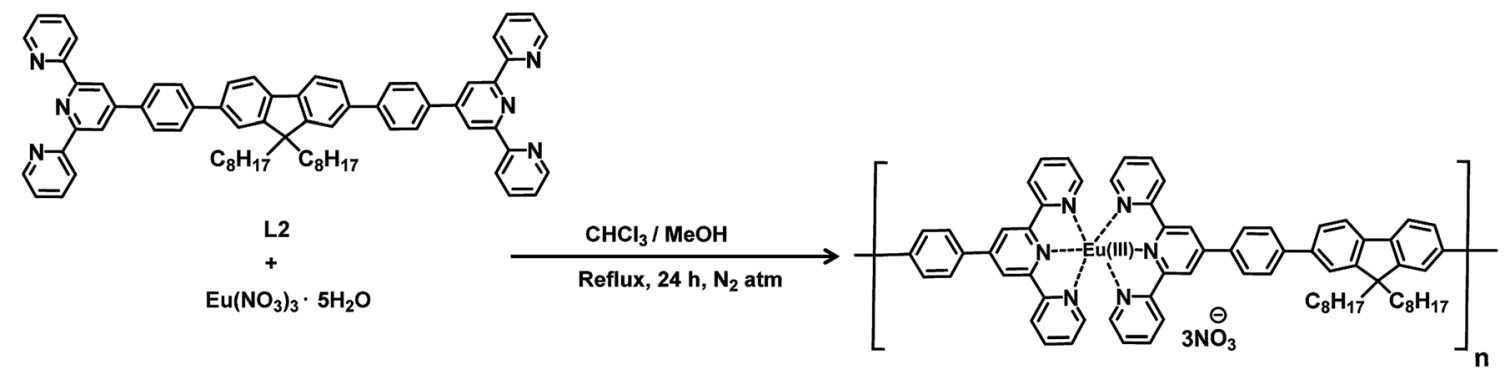

PolyEu-2, Yield 90\%

Fig. 4 Synthesis of PolyEu-2. 


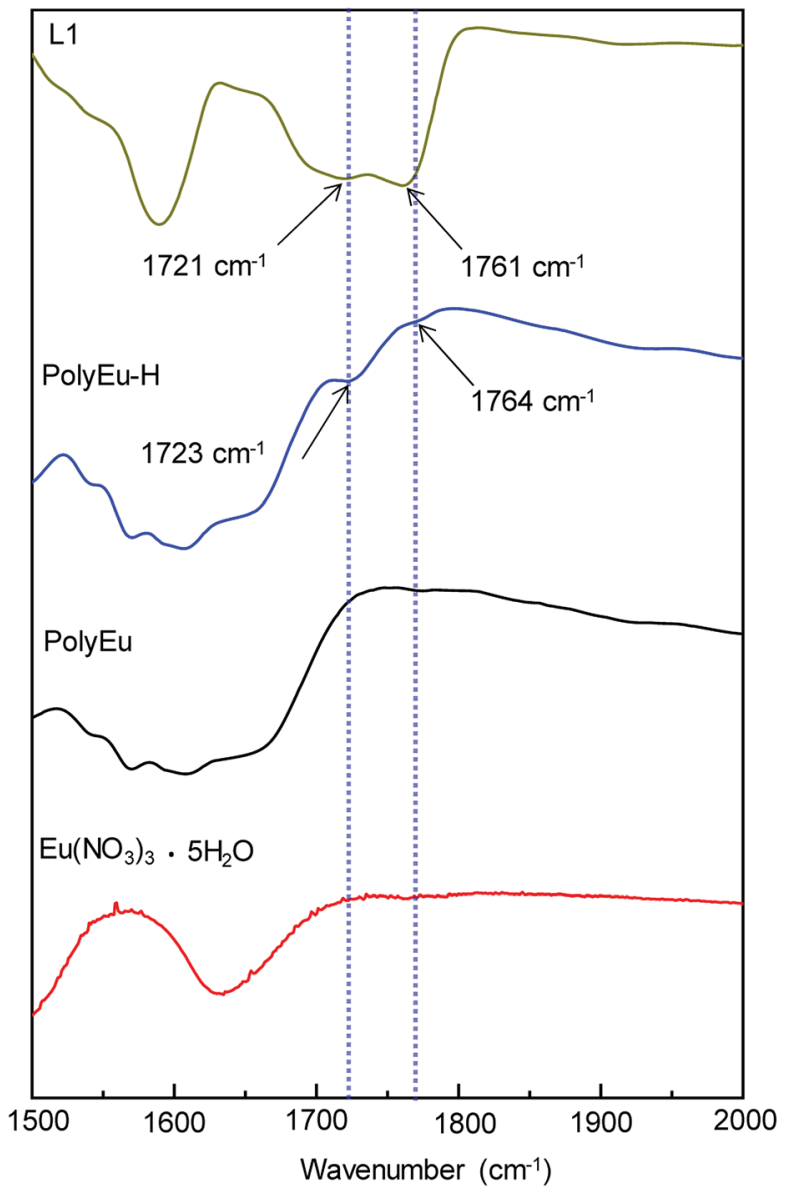

Fig. 5 FT-IR spectra of L1, PolyEu-H, PolyEu, and $\mathrm{Eu}\left(\mathrm{NO}_{3}\right)_{3}$.

white, white and reddish blue color emissions, respectively under the UV-irradiation.

The presence of free carboxylic groups in PolyEu-H was confirmed by using FT-IR spectrum (Fig. 5 and S17, ESI†). Fig. 5 shows the FT-IR spectra $\left(1500-2000 \mathrm{~cm}^{-1}\right)$ of L1, PolyEu-H, PolyEu, and $\mathrm{Eu}\left(\mathrm{NO}_{3}\right)_{3}$. Comparing these spectra, we found that the peaks at 1721 and $1761 \mathrm{~cm}^{-1}$ which are the stretching vibration frequencies corresponding to the $\mathrm{C}=\mathrm{O}$ of free $\mathrm{COOH}$ in L1. Similar peaks with a small blueshift at 1723 and $1764 \mathrm{~cm}^{-1}$ appeared in PolyEu-H. The small shift of these peaks probably due to the interaction between $\mathrm{C}=\mathrm{O}$ with $\mathrm{Eu}$ in PolyEu-H. This results clearly indicate the presence of free carboxylic acids in PolyEu-H. In PolyEu, no peaks were found at 1721 and $1761 \mathrm{~cm}^{-1}$ because of no free carboxylic acids in PolyEu. We also have done the qualitative analysis to find out the free carboxylic acids in PolyEu-H. The deprotonation of carboxylic acids leads to changes in the electronic structure of complexes. This change can have the notable effect on optical properties of the complexes. The deprotonation of carboxylic acids results in the blue shift in the absorption of the compound. $^{40,41}$ The major effect of deprotonation on the addition of triethylamine ( $\mathrm{Et}_{3} \mathrm{~N}$ to PolyEu-H) of free carboxylic acids in PolyEu-H was observed in the absorption of it. The determined blue-shift of the absorption maximum of PolyEu-H compared to that in the corresponding protonated PolyEu-H (Fig. S18, ESI $\dagger$ ). This result clearly indicated that PolyEu-H having free carboxylic acid groups.

We also studied the morphology of polymers using AFM in the dynamic mode and SEM. A dilute solution of polymers in DMSO or dispersion of polymers in $\mathrm{MeOH}$ solvent drop cast on a silicon wafer and allowed to dry. The AFM examination of polymers (PolyEu-H, PolyEu, and PolyEu-2) revealed the several spherical individual particles and aggregated particles. AFMcross section analysis of the spherical particles showed that the height and diameter in the range of 1-30 nm and 20-200 nm in diameter (Fig. S19, S21 and S23, ESI $\dagger$ ). For SEM analysis, polymer solution drop cast on the glass slide. SEM analysis also confirmed spherical particles formed of polymers dimension in the nanoscale (Fig. S20, S22, and S24, ESI†). Probably, due to increasing the close packing of the hydrophobic octyl chains on the fluorene rings forming spherical-like structures of polymers. The SEM and AFM analysis indicate that all the polymers have shown a similar kind of morphology.

The proton conductivity of PolyEu-H, PolyEu, and PolyEu-2 (powder samples) were determined by an ac impedance technique using polymer pellets by Solartron 1260 Impedance gain/ phase analyzer coupled with a Solartron 1296 dielectric interface. The pellet thickness of all the polymers was in the range of $0.01-0.03 \mathrm{~cm}$ and a diameter of $3.0 \mathrm{~mm}$. Fig. 6a shows the Nyquist plot for the conductivity measurement of PolyEu-H at $25{ }^{\circ} \mathrm{C}$ and $95 \%$ RH and PolyEu, PolyEu-2 have shown in Fig. S25 and S26a (ESI). $\dagger$ The resistance of polymers was calculated from
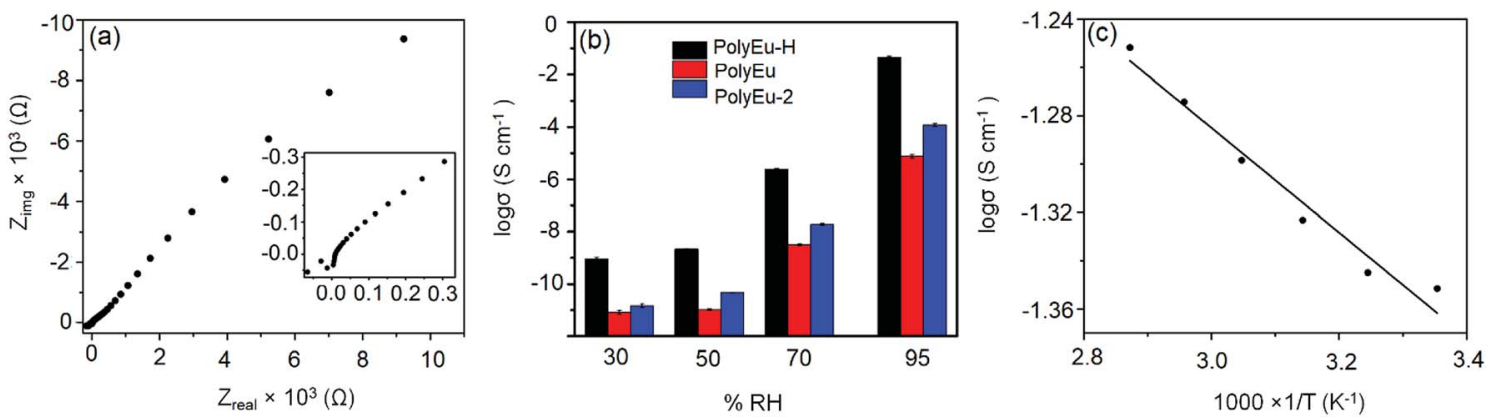

Fig. 6 (a) The Nyquist plots for proton conductivity at $25^{\circ} \mathrm{C}$ and $95 \% \mathrm{RH}$ for PolyEu-H (frequency range: $1 \mathrm{~Hz}$ to $30 \mathrm{MHz}$ ); inset showed the high frequency region. (b) The comparative graph of log(conductivity) and relative humidity (30, 50, 70 and $95 \% \mathrm{RH}) \mathrm{Of}(\mathrm{PolyEu}-\mathrm{H}$, PolyEu, and PolyEu-2) (c) activation energy determination of PolyEu- $\mathrm{H}$ at $95 \% \mathrm{RH}$. 
the $x$-axis intercept of the semicircle at higher frequencies. In PolyEu-H, at 95\% RH a semicircle does not appear due to the very high conductance. Hence, the conductivity was calculated from the $x$-intercept of the plot in the high-frequency region. However, at low \% RH the semicircle appeared in the PolyEu-H, the Nyquist plots at the same frequencies were presented in Fig. S27a, S28a, and S29a (ESI). $\dagger$ By using the calculated dimensions of polymer pellets, the proton conductivity of polymers (PolyEu-H, PolyEu, and PolyEu-2) were calculated to be $4.45 \times 10^{-2}, 7.58 \times 10^{-6}$, and $1.17 \times 10^{-4} \mathrm{~S} \mathrm{~cm}^{-1}$, respectively, at $95 \% \mathrm{RH}$ and $25{ }^{\circ} \mathrm{C}$. Additionally, PolyEu-H showed highest conductivity $5.60 \times 10^{-2}$ at $75{ }^{\circ} \mathrm{C}$. Interestingly, the observed proton conductivity of PolyEu-H is comparable and higher than the reported literature proton conductivity of porous materials at the similar experimental conditions (Table S1, ESI $\dagger$ ). In PolyEu, the conductivity was drastically dropped to $7.58 \times 10^{-6} \mathrm{~S} \mathrm{~cm}^{-1}$, in PolyEu, there are no free carboxylic acids as like in PolyEu-H and no possibility to coordinate additional water molecules also. In the presence of the base, all carboxylic acids in L1 were converted into carboxylate ions and these carboxylate ions coordinated to $\mathrm{Eu}(\mathrm{III})$ ion to form ten coordinated complexes of PolyEu (Fig. 3). The role of free carboxylic acids in conduction was further proved by measurement of the proton conductivity of PolyEu-2. In PolyEu-2, the conductivity was dropped sharply to $1.17 \times 10^{-4} \mathrm{~S} \mathrm{~cm}^{-1}$. It is to be noted that unlike in PolyEu-H, there are no additional proton carrier molecules in PolyEu-2, and hence the number of total proton carriers is much less in PolyEu-2 compared with the PolyEu-H. However, PolyEu-2 was showed more proton conductivity than PolyEu, probably because of its six coordinated complexes are shown in Fig. 4.

The europium can form variable coordination number complexes with terpyridine derivatives depending upon environment. ${ }^{\mathbf{4 2 - 4 6}}$ Even though many techniques have been used for the determination of the coordination number of lanthanide ions in complexes (e.g., UV-Visible spectroscopy, luminescence, $\mathrm{X}$-ray diffraction, and conductivity), but only X-ray diffraction can give precise answers. ${ }^{47-50}$ Unfortunately, this method is usually particular to crystalline complexes. Under the humid condition, Eu(III) ion in PolyEu-2 can form eight coordination complexes with six from nitrogen atoms of two terpyridine moieties and two from water molecules. So, these coordinated water molecules can form $\mathrm{H}_{3} \mathrm{O}^{+}$species with other water molecules. Then the $\mathrm{H}_{3} \mathrm{O}^{+}$species as proton carriers move across a self-diffusion process in the polymer chain to contribute to the proton conduction. Therefore, the total number of water molecules accommodated in PolyEu-2 is more compared with the PolyEu.

Under the humid condition, in PolyEu-H the hydrogen on free carboxylic acid forms a hydrogen bond with the oxygen atom of water molecules to make an extended hydrogen bonding network. The free water molecules can accept protons which are dissociated from free carboxylic acid, forming $\mathrm{H}_{3} \mathrm{O}^{+}$. Then, the proton is transferred by an alternate formation and breaking of hydrogen bonds at suitable positions for proton hopping across the extended hydrogen-bonding network. The strong hydrogen bonding network, formed by the carboxylic
Table 1 Proton conductivity of PolyEu-H, PolyEu, and PolyEu-2 at 30, 50,70 and $95 \% \mathrm{RH}$

\begin{tabular}{llll}
\hline & \multicolumn{2}{l}{ Proton conductivity $(\sigma) \mathrm{S} \mathrm{cm}^{-1}$} & \\
\cline { 2 - 3 } & PolyEu-H & PolyEu & PolyEu-2 \\
\hline 30 & $9.15 \times 10^{-10}$ & $8.35 \times 10^{-12}$ & $1.48 \times 10^{-11}$ \\
50 & $2.15 \times 10^{-9}$ & $1.11 \times 10^{-11}$ & $4.70 \times 10^{-11}$ \\
70 & $2.40 \times 10^{-6}$ & $3.19 \times 10^{-9}$ & $1.90 \times 10^{-8}$ \\
95 & $4.45 \times 10^{-2}$ & $7.58 \times 10^{-6}$ & $1.17 \times 10^{-4}$ \\
\hline
\end{tabular}

acids of PolyEu-H with water molecules and generate high carrier concentrations, facilitates this high proton conductivity.

In order to analyze the kinetics of the proton conduction, the conductivity of PolyEu-H and PolyEu-2 were also measured at a range of temperatures $\left(25-75{ }^{\circ} \mathrm{C}\right)$ and Arrhenius plots were obtained at 95\% RH as well as at 70\% RH (Fig. 6c, S26c, d and S30a (ESI) $\dagger$ ) activation energy value of $0.04 \mathrm{eV}$ at $95 \% \mathrm{RH}$ and which was eight times lower than PolyEu-2 $(0.33 \mathrm{eV})$. At 70\% RH of $E_{\text {a }}$ of PolyEu-H and PolyEu-2 were 0.14, $0.40 \mathrm{eV}$. Remarkably, PolyEu-H showed the low $E_{\mathrm{a}}$ than commercially available standard PEMFC Nafion $\left(E_{\mathrm{a}}=0.22 \mathrm{eV}\right)$ and also lower $E_{\mathrm{a}}$ value than the reported proton conducting materials till date (Table S2, ESI $\dagger$ ). The comparative Nyquist plots of PolyEu-H, PolyEu, and PolyEu-2 at 30\%, 50\% and 70\% RH and temperature dependence plot of PolyEu-H and PolyEu-2 at 95\% RH were presented in Fig. S27-S29 and S31 (ESI) $\dagger$ and the proton conductivity data was presented in Table 1 . The low activation energies of PolyEu$\mathbf{H}$ and PolyEu-2 $(<0.4 \mathrm{eV})$ indicates that the possible proton conduction by the Grotthuss mechanism. ${ }^{16,51}$ The proton conductivity of polymers was very much sensitive to humidity: the rapid increase in the proton conductivity while increasing the humidity from 30 to $95 \%$ RH (Fig. 6b, S26b and S30b (ESI) $\dagger$ ). This result clearly indicates that water molecules in the polymer play a significant role in creating the proton conduction channels.

We also examined the reproducibility of proton conduction by measuring the three times on different sets of polymers (PolyEu-H, PolyEu, and PolyEu-2) samples. Individually experiment shown comparable results with good reliability, emphasized by standard deviations in Fig. $6 \mathrm{~b}$ not exceeding $\pm 7 \%$. Finally, the polymers showed the drastic difference in the proton conductivity values, this is probably due to the difference in their coordination structures in the polymer chain.

\section{Conclusion}

There are several reports on proton conduction of lanthanidebased metal-organic frameworks. We summarized some of them in the Table S3. $\dagger$ We firstly synthesized europium(III)based MSP with uncoordinated carboxylic acids coordination structure PolyEu-H, for high proton conduction. The conductivity of the polymer increases with increasing relative humidity. This approach of employing with and without carboxylic acids containing ligands as homoditopic ligands to construct metallo-supramolecular polymers with free carboxylic acids as remarkable conductive materials for applications has the 
potential to explore wide areas. PolyEu-H have shown proton conductivity $4.45 \times 10^{-2} \mathrm{~S} \mathrm{~cm}^{-1}$ with low activation energy $E_{\mathrm{a}}=$ $0.04 \mathrm{eV}$ at $95 \% \mathrm{RH}$ and also achieved higher proton conduction $5.6 \times 10^{-2} \mathrm{~S} \mathrm{~cm}^{-1}$ at $75^{\circ} \mathrm{C}$.

\section{Conflicts of interest}

There are no conflicts to declare.

\section{Acknowledgements}

This work was supported by JST CREST Grant Number JPMJCR1533, Japan.

\section{References}

1 A. Winter and U. S. Schubert, Chem. Soc. Rev., 2016, 45, 5311.

2 G. R. Whittell, M. D. Hager, U. S. Schubert and I. Manners, Nat. Mater., 2011, 10, 176.

3 C. E. D. Chidsey and R. W. Murray, Science, 1986, 231, 25.

4 D. J. Caruana and A. Heller, J. Am. Chem. Soc., 1999, 121, 769.

5 R. J. Mortimer, A. L. Dyer and J. R. Reynolds, Displays, 2006, 27, 2.

6 Q. Zeng, A. McNally, T. E. Keyes and R. J. Forster, Electrochem. Commun., 2008, 10, 466.

7 L. Dennany, R. J. Forster, B. White, M. R. Smyth and J. F. Rusling, J. Am. Chem. Soc., 2004, 126, 8835.

8 M. Higuchi, J. Mater. Chem. C, 2014, 2, 9331.

9 J. A. Hurd, R. Vaidhyanathan, V. Thangadurai, C. I. Ratcliffe, I. L. Moudrakovski and G. K. H. Shimizu, Nat. Chem., 2009, 1, 705.

10 B. C. Steele and A. Heinzel, Nature, 2001, 414, 345.

11 K. D. Kreuer, Chem. Mater., 1996, 8, 610.

12 K. D. Kreuer, S. J. Paddison, E. Spohr and M. Schuster, Chem. Rev., 2004, 104, 4637.

13 J. Peron, Z. Shi and S. Holdcroft, Energy Environ. Sci., 2011, 4, 1575.

14 N. Yamazoe and Y. Shimizu, Sens. Actuators, 1986, 10, 379.

15 T. Yamada, K. Otsubo, R. Makiura and H. Kitagawa, Chem. Soc. Rev., 2013, 42, 6655.

16 M. Sadakiyo, T. Yamada and H. Kitagawa, J. Am. Chem. Soc., 2009, 131, 9906.

17 A. Shigematsu, T. Yamada and H. Kitagawa, J. Am. Chem. Soc., 2011, 133, 2034.

18 M. Sadakiyo, T. Yamada and H. Kitagawa, J. Am. Chem. Soc., 2014, 136, 7701.

19 S. Bureekaew, S. Horike, M. Higuchi, M. Mizuno, T. Kawamura, D. Tanaka, N. Yanai and S. Kitagawa, Nat. Mater., 2009, 8, 831.

20 B. Joarder, J.-B. Lin, Z. Romero and G. K. H. Shimizu, J. Am. Chem. Soc., 2017, 139, 7176.

21 D. M. DeLongchamp and P. T. Hammond, Chem. Mater., 2003, 15, 1165.

22 C. Tiyapiboonchaiya, J. M. Pringle, J. Sun, N. Byrne, P. C. Howlett, D. R. MacFarlane and M. Forsyth, Nat. Mater., 2004, 3, 29.
23 X. Kuang, M. A. Green, H. Niu, P. Zajdel, C. Dickinson, J. B. Claridge, L. Jantsky and M. J. Rosseinsky, Nat. Mater., 2008, 7, 498.

24 M. Li, M. J. Pietrowski, R. A. De Souza, H. Zhang, I. M. Reaney, S. N. Cook, J. A. Kilner and D. C. Sinclair, Nat. Mater., 2014, 13, 31.

25 K. Schmidt-Rohr and Q. Chen, Nat. Mater., 2008, 7, 75.

26 R. Haugsrud and T. Norby, Nat. Mater., 2006, 5, 193.

27 D. Pergolesi, E. Fabbri, A. DEpifanio, E. Di Bartolomeo, A. Tebano, S. Sanna, S. Licoccia, G. Balestrino and E. Traversa, Nat. Mater., 2010, 9, 846.

28 S. Chandra, T. Kundu, S. Kandambeth, R. Baba Rao, Y. Marathe, S. M. Kunjir and R. Banerjee, J. Am. Chem. Soc., 2014, 136, 6570.

29 R. K. Pandey, M. D. Hossain, S. Moriyama and M. Higuchi, J. Mater. Chem. A, 2013, 1, 9016.

30 R. K. Pandey, M. D. Hossain, S. Moriyama and M. Higuchi, J. Mater. Chem. A, 2014, 2, 7754.

31 R. K. Pandey, M. D. Hossain, T. Sato, U. Rana, S. Moriyama and M. Higuchi, RSC Adv., 2015, 5, 49224.

32 R. K. Pandey, C. Chakraborty, U. Rana, S. Moriyama and M. Higuchi, J. Mater. Chem. A, 2016, 4, 4398.

33 R. K. Pandey, M. D. Hossain, C. Chakraborty, S. Moriyama and M. Higuchi, Chem. Commun., 2015, 51, 11012.

34 R. K. Pandey, U. Rana, C. Chakraborty, S. Moriyama and M. Higuchi, ACS Appl. Mater. Interfaces, 2016, 8, 13526.

35 C. Chakraborty, U. Rana, R. K. Pandey, S. Moriyama and M. Higuchi, ACS Appl. Mater. Interfaces, 2017, 9, 13406.

36 L. Ungur and L. F. Chibotaru, Inorg. Chem., 2016, 55, 10043. 37 R. Yu and L. C. D. Jonghe, J. Phys. Chem. C, 2007, 111, 11003. 38 T. Sato and M. Higuchi, Chem. Commun., 2012, 48, 4947.

39 F. S. Han, M. Higuchi and D. G. Kurth, Org. Lett., 2007, 9, 559.

40 C. Klein, M. K. Nazeeruddin, D. D. Censo, P. Liska and M. Gratzel, Inorg. Chem., 2004, 43, 4216.

41 N. Nickita, M. J. Belousoff, A. I. Bhattt, A. M. Bond, G. B. Deacon, G. Gasser and L. Spiccia, Inorg. Chem., 2007, 46, 8638.

42 R. D. Chapman, R. T. Loda, J. P. Riehl and R. W. Schwartz, Inorg. Chem., 1984, 23, 1652.

43 P. Chen, Q. Li, S. Grindy and N. H. Andersen, J. Am. Chem. Soc., 2015, 137, 11590.

44 P. Coppo, M. Duati, V. N. Kozhevnikov, J. W. Hofstraat and L. De Cola, Angew. Chem., Int. Ed., 2005, 44, 1806.

45 E. S. Andreiadis, R. Demadrille, D. Imbert, J. P. caut and M. Mazzanti, Chem.-Eur. J., 2009, 15, 9458.

46 A. J. Amoroso, M. W. Burrows, R. Haigh, M. Hatcher, M. Jones, U. Kynast, K. M. A. Malika and D. Sendor, Dalton Trans., 2007, 1630.

47 D. E. Karraker, Inorg. Chem., 1968, 7, 473.

48 J. C. G. Bunzli and M. Vuckovic, Inorg. Chim. Acta, 1983, 73, 53.

49 J. Albertsson, Acta Chem. Scand., 1970, 24, 1213.

50 F. H. Spedding and G. Atkinson, The Structure of Electrolyte Solutions, Wiley, New York, 1959, ch. 2.

51 N. Agmon, Chem. Phys. Lett., 1995, 244, 456. 